Academic Medicine, 2005, Volume 80, Issue 11, Pages 1026-1031.

ISSN: 1040-2446

Link to Academic Medicine Homepage.

Link to article on Academic Medicine website.

This is a non-final version of an article published in final form in (Academic Medicine, 2005)

(C) 2005 Association of American Medical Colleges

\title{
Managing Knowledge and Technology to Foster Innovation at The Ohio State University Medical Center
}

\author{
Timothy J. Cain, PhD, Ruey L. Rodman, MLS, Fred Sanfilippo, MD, PhD, and \\ Susan M. Kroll, MLS
}

Dr. Cain is adjunct assistant professor of biomedical informatics and director of Internet strategies and learning technologies, Center for Knowledge Management, The Ohio State University Medical Center, Columbus, Ohio.

Ms. Rodman is associate professor of university libraries and instruction services coordinator, John A. Prior Health Sciences Library at The Ohio State University Medical Center, Columbus, Ohio.

Dr. Sanfilippo is dean of The Ohio State University College of Medicine and Public Health, senior vice president and executive dean for health sciences, and chief executive officer, The Ohio State University Medical Center, Columbus, Ohio.

Ms. Kroll is associate vice president for health sciences and director of the John A. Prior Health Sciences Library, The Ohio State University Medical Center, Columbus, Ohio.

\section{Abstract}

Biomedical knowledge is expanding at an unprecedented rate-one that is unlikely to slow anytime in the future. While the volume and scope of this new knowledge poses significant organizational challenges, it creates tremendous opportunities to release and direct its power to the service of significant goals. The authors explain how the Center for Knowledge Management at The Ohio State University Medical Center, created during the academic year 2003-04, is doing just that by integrating numerous resource-intensive, technology-based initiatives - including personnel, services and infrastructure, digital repositories, data sets, mobile computing devices, high-tech patient simulators, computerized testing, and interactive multimedia - in a way that enables the center to provide information tailored to the needs of students, faculty and staff on the medical center campus and its surrounding health sciences colleges.

The authors discuss how discovering, applying, and sharing new knowledge, information assets, and technologies in this way is a collaborative process. This process creates open-ended opportunities for innovation and a roadmap for working toward seamless integration, synergy, and substantial enhancement of the academic medical center's research, educational, and clinical mission areas. 
In this article, we describe the creation of a unique and innovative knowledge management organization closely aligned with a library at an academic medical center. The challenges encountered, efficiencies achieved, and synergies realized through our alignment of informational resources, state-of-the-art technologies, and expert personnel have enabled us to streamline delivery of information and educational resources, enhance technology support, and foster knowledge-based innovations at The Ohio State University Medical Center (OSUMC).

\section{Introduction}

The digital age is revolutionizing research, education, and patient care in the modern academic medical center as it brings complex molecular, genomic, and proteomic maps, interactive learning objects, and complete patient record sets to the fingertips of users. At the OSUMC - an organization that includes a medical college, allied health, and biomedical science schools, five hospitals, and network of central Ohio outpatient care facilities — our interconnected laboratories allow investigators to share data sets and leverage computing resources across traditional disciplines and institutional boundaries. Our students are immersed in learning environments enriched with digital multimedia, high-tech patient simulators, and digital library resources that enable them to gather and use knowledge in new, innovative ways. Clinical care benefits greatly as well; for instance, our clinicians may, by exploring warehouses of clinical data, analyze digitized tissue biopsy specimens, pull diagnostic patient data (e.g., laboratory test results) to a hand-held electronic device, and discover treatment efficacies.

While it is natural to focus on the value of technology in these examples, it is crucial to recognize that they cannot be successfully completed without the convergence and dynamic interaction of three important elements: data (facts and figures), processes (technology and context), and know-how or understanding (people and expertise). These three elements constitute a concept defined and embraced in business circles as knowledge management.

The ability to manage and assimilate the constantly growing pool of information, technology, and human expertise creates unique challenges for researchers, educators, clinicians, and students in the modern academic medical center. To meet the needs of these user communities at our academic medical center, the Center for Knowledge Management (CKM) was created on the OSUMC campus during academic year 2003-04. The new center was chartered to leverage the strengths of people, processes, data, and technology in order to foster the creation, analysis, dissemination, and utilization of knowledge. Integrating these activities amplifies the value of knowledge-based assets and grows from and enhances the medical center's commitment to excellence in biomedical research, graduate and health care education, and patient care.

\section{The Concept of Knowledge Management}

The concept of knowledge management (KM) finds its roots in corporate arenas where business leaders face mergers, acquisitions, and a highly mobile workforce in the new global marketplace. In their haste to reduce costs, consolidate staffing, and streamline processes, 
however, business managers often have eliminated key personnel whose knowledge of product lines, methodologies, and services left with them. As one CEO remarked: "Every afternoon our corporate knowledge walks out the door and I hope to God they'll be back tomorrow." "As a result, business leaders have recognized that in order to maintain competitive advantage and viability they need to document and codify the expertise and know-how of their workforce. This process formed the seed of knowledge management.

First described by Davenport and Prusak in the mid-1990s, KM initially emerged as a methodology that allowed companies to supplant the disruptive and growing trend toward frequent corporate retooling with a more productive approach. ${ }^{2,3}$ As others have noted, KM is not merely a byproduct of the interaction of information and technology; to function, it also requires the input, expertise, and intuition of the staff who interface with and guide the data and processes throughout overlapping stages: knowledge creation, knowledge application, and knowledge dissemination. ${ }^{4,5}$ To implement KM, businesses often name chief knowledge officers charged with creating and fostering communities of practice within the organization in order to better understand what knowledge employees possess and how they organize it, share it, and apply it to decision making. These resulting knowledge networks leverage technology to create Webaccessible portals that deliver customized information on professional development, peer-to-peer mentoring, and electronic collaboration tools, as well as knowledge profiles and other just-intime tools to the desktops of each employee. ${ }^{6}$ The strategy has proven successful; for example, when the United States Navy deployed a KM portal allowing delivery of customized, realtime information to its enlisted service personnel stationed around the globe, they noted greater operational efficiency and the elimination of costly redundancies. ${ }^{7}$

While the formal concept of KM may seem new to academic medicine and higher education in general, its fundamental principles and practices actually find their genesis in the academy. The KM principles of codifying, communicating and mentoring are found not only in university libraries, but in laboratories, classrooms, clinics and hospitals, conferences, and publications. Biomedical knowledge, forged as raw data in research laboratories and clinics, derives meaning and context from the formal training and experience of the research teams designing the protocols, collecting the data, and interpreting the findings. Such knowledge would add little to our collective understanding if these teams failed to record their findings, vet through peer review, or publish for the scientific community to read. This newly acquired knowledge, organized and made accessible in libraries, is shared among faculty colleagues and the trainees they mentor and ultimately translated into new therapies for the patients treated ac ademic medical centers. The academic medical center's commitment to research, teaching, and patient care maps directly to the KM tenets of creating, sharing, and applying knowledge. In fact, in a very real way, this is the whole of the academic medical center's mission.

The challenge of managing knowledge in an academic medical center results not only from the immense volume of data now available, but also from the way knowledge has been affected by dramatic changes in medical education, the introduction of evidence-based medicine, and the expansion of information systems to provide information access and to generate and harness data in a meaningful way. 


\section{Libraries - A Natural Fit}

If any group in the academic community has anticipated the future in terms of managing the rapidly expanding pool of knowledge and digital information, it is librarians. The 1990s witnessed the advent of digital collections and repositories, electronic journals, and electronic indices. $^{8-11}$ Even before the World Wide Web brought information to tens of millions of individuals around the globe, Lucier ${ }^{12}$ challenged his colleagues in 1995 to think boldly about a future where the library could become an information space rather than information place. Librarians are readily identified as the campus experts in discerning quality resources for information and knowledge and providing users with effective strategies for retrieving them. Discussing their seminal book on managing knowledge, Davenport and Prusak wrote that the stewardship of high-quality knowledge has always been at the center of a librarian's mission and that this role continues to evolve. ${ }^{13}$ Stern $^{14}$ tasks his readers to "influence the future . . . review and revise current tools ... educate all players about the essential aspects of scholarly information transfer systems." Vasallo ${ }^{15}$ notes that in the knowledge continuum, libraries have traditionally been very active in the discovery process, and now can increase their expertise and involvement in dissemination, particularly in the areas of copyright, management of intellectual assets, and commercialization.

This relationship of the library and its staff to the stewardship and uses of knowledge made the John A. Prior Health Sciences Library on the OSUMC campus the logical administrative and physical home for the CKM. Renovated in the mid-1990s, the Prior Library is centrally located on the OSU health sciences campus and serves a broad constituency - the faculty, staff, and students of the Colleges of Medicine and Public Health, Dentistry, Nursing, Optometry, Pharmacy, and Veterinary Medicine as well as the researchers, clinical faculty and staff, and patients of the five hospitals and network of central Ohio outpatient care facilities of the OSU Health System.

Traditionally, academic health sciences libraries have served as test markets for advances in informational sciences, and they have grown accustomed to the changes and challenges that new technologies bring. Over the past 30 years, the Internet, digital collection management, and electronic indices have changed libraries from information places to the keepers of information space. Information seekers now have round-the-clock access to library information, collections, and services from their offices and even living rooms.

The Association of Academic Health Sciences Libraries has stated that libraries are at the crossroads of redefining not only the use of library space, but also the traditional role of librarians as information providers. ${ }^{16}$ Bell and Shenk ${ }^{17}$ go even further, writing that academic librarians must augment their traditional information-processing skills with those of technologists and instructional designers to meet the demands of the broader role libraries now serve. The rapidly rising tide of technology, and the demand for fingertip access to information, does not afford libraries or academic medical centers the luxury of waiting for the next generation of professionals to be trained.

At our institution, we have already begun teaming librarians with information technology (IT) and educational technology specialists, which has positioned us to integrate and transform 
information services, research stewardship, and educational support into knowledge management and help foster intellectual assets and products. Our library's open and flexible space and its state-of-the-art wired and wireless networking infrastructure make the facility an ideal location for accommodating the information and technology support needs of our medical center's users.

\section{Theory into Practice}

To bolster the academic medical center mission, biomedical knowledge in our institution and around the world must be handled with an eye to access, synergy, and creation of value. However, the process of creating this synergy by managing, integrating, and sharing this constantly growing pool of information and knowledge in a seamless fashion creates unique practical challenges. Interconnecting disparate data sets contained in proprietary, clinical, and information software systems; balancing the juxtaposed need for protective firewalls and lessrestrictive, high-throughput networks; providing our students and clinical and research faculty with access to digital clinical image sets while protecting patient confidentiality; and supporting every flavor of mobile computing device (e.g., pagers, personal digital assistants, laptop computers) taxes even the most agile administrators and technical support teams. Undaunted, the CKM leadership team pursued these challenges with the goal of optimizing organizational alignments, identifying untapped efficiencies, and leveraging our knowledge assets, which ultimately has allowed us to bring enhanced and expanded value to our community of users.

While others have successfully coupled medical education and biomedical informatics to synergize educational scholarship, services and support, ${ }^{18}$ we began exploring ways to more effectively manage and support the academic IT and knowledge needs across all three mission areas of research, education, and patient care. Toward this end, we established the following goals and objectives:

\section{Creating knowledge}

- Develop and assimilate new knowledge-based products that enhance excellence in biomedical research, health sciences education, and patient care.

- Package informational resources as discrete, reusable, and sharable resources that enhance work collaborations.

\section{Using knowledge}

- Preserve original biomedical data of historical value.

- Disseminate knowledge in biomedical research, education, and clinical practice consistent with our mission.

Sharing knowledge

- Enable cost-effective, timely, and convenient access to biomedical knowledge.

- Provide a challenging and supportive environment to foster professional growth of staff and trainees.

- Strengthen digital linkages across the Health Sciences campus and the university to foster collaboration in knowledge development, sharing, and dissemination. 
The value of centralizing IT support teams into a single physical and administrative location was obvious, and laid the groundwork for creating the CKM within the Prior Library. In this central location, the CKM has allowed us to streamline the support of academic IT needs and better manage knowledge-based resources across the medical center campus.

In July 2003, three IT support teams from disparate administrative areas of the academic medical center were relocated to renovated space within the library. Each group arrived with preestablished yet varying financial models, customer bases, repertoire of IT services, and organizational cultures. With guidance from organizational development staff, the three teams explored opportunities for refocusing and enhancing alignments of their services, support, and product mix. During these early stages, economies of scale were appreciated by identifying new opportunities and consolidating duplicate services. Centralizing, coordinating, and consolidating the support services offered by the three initial teams (1) gave medical center customers a single point of entry, (2) enhanced cross-training of personnel, and (3) expanded the breadth and depth of services that could be offered.

\section{Challenges}

To be fair, our implementation efforts with the CKM have not come without challenges.

Space. While its location within the medical center campus has made the Prior Library an ideal spot for centralizing academic IT services, accommodating the influx of 25 relocated staffers created some obvious challenges. New offices and service desks needed to be constructed, dramatically reducing the footprint of public study space by an estimated one-third on an entire floor.

Change. Moving people, modifying workflow dynamics, and realigning responsibilities are never without challenges. Identifying and fostering appropriate synergies between teams derived from disparate administrative areas, service modalities, and customer bases cannot be underestimated. We continue to look for convergence points between library, educational, and IT support services where they make sense, while recognizing and accommodating the unique needs and challenges of the aligned units.

Growth. The ubiquity of technology and knowledge-based systems across mission areas continues to drive demand for expertise, infrastructure, training, and support. Keeping up with this demand, anticipating what the next operating system or application release will bring, and having staff trained and ready to support the next mobile computing device that finds its way into users' hands all challenge the most agile of support teams. We have and will continue to experience these and other growing pains as the CKM evolves.

\section{Realignments and support services}

Concomitant to the evolution of the CKM, major strategic realignments have been occurring within the IT organization that serves our OSU Health System, its five hospitals, and 
network of central Ohio outpatient care facilities. Appointed in 2004, our chief information officer began developing a shared IT services model across major business units, established a shared governance structure spanning all mission areas, and began optimizing alignment of IT resource allocation with the medical center's strategic plan. As a result, efficiencies and economies of scale have been realized with key enterprise-level IT support and services (e.g., networking infrastructure, data warehousing, e-mail, telecommunications, business application support). Currently aligned as an academic partner, the CKM works closely with the health system's IT organization, with ongoing synergies and alignments continuing to evolve.

\section{Table 1}

Support and Services Offered through the Center for Knowledge Management, The Ohio State University Medical Center, 2005*

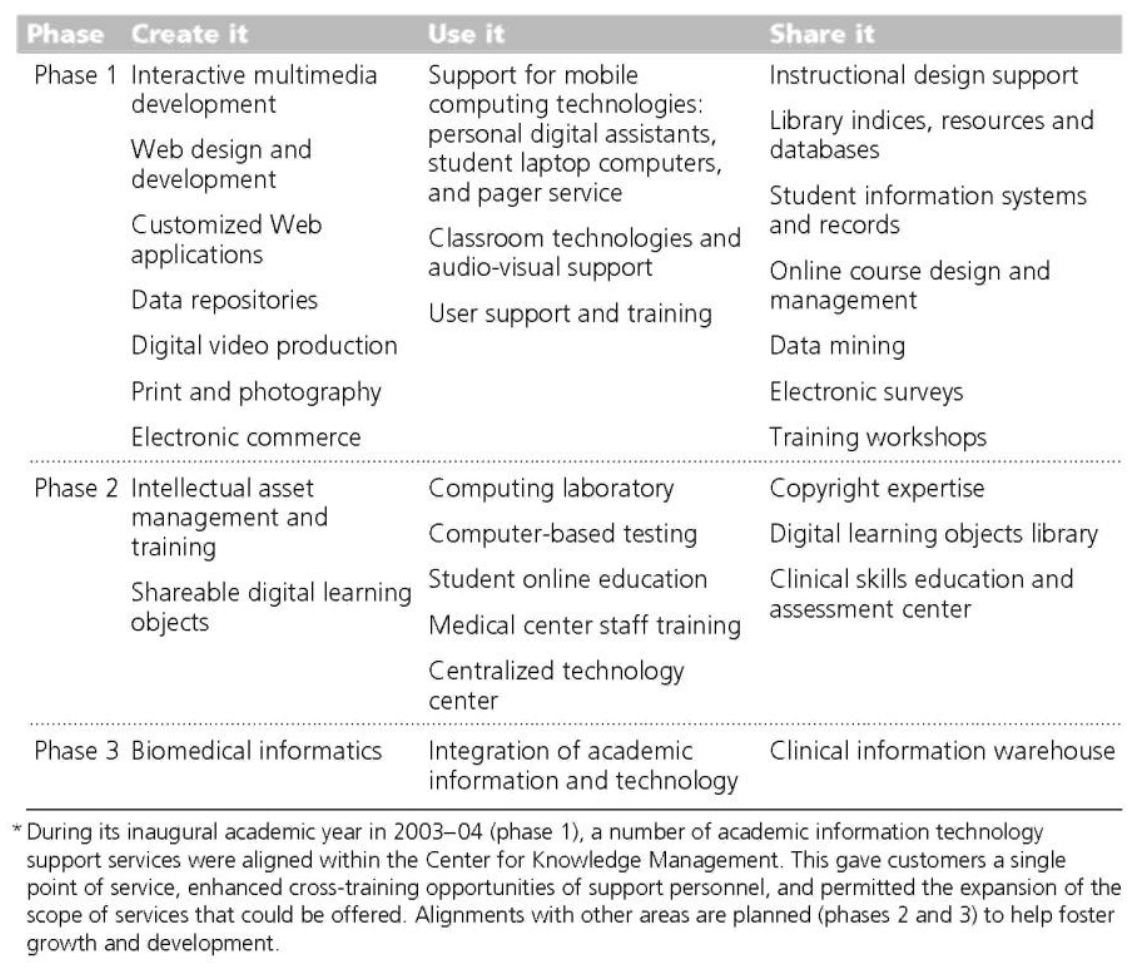

Since its inception, the audiences and the support services offered for them through the CKM have included:

Students. Mobile computing devices (e.g., laptop computers, personal digital assistants, pagers), document searches, online educational resources, electronic student records, computer-based testing facilities

Researchers: faculty and research scientists. Literature reviews, research data sets and mining tools, funding opportunities, technology commercialization, intellectual property, poster production, Web applications and tool 
Clinical and teaching faculty. Instructional design, online course development, best practices in using instructional technologies, design support for digital learning objects, copyright expertise, educational scholarship, literature searches for clinical reviews and studies

Administration. Reporting tools using integrated canonical data sets, online surveys and assessment instruments, benchmarking and metrics, quality, safety, demographics data

Community. Educational tools, quality health information

\section{New initiatives}

The CKM's early successes in blending personnel, services, and support infrastructure have made it possible to establish several new, technology-intensive, knowledge-based initiatives (see Table 1). Some of these are described below.

Computer-based student assessment. To facilitate processing of medical student examinations, incorporation of multimedia into exams, and improvement of examination score reporting and item analysis, we began piloting computer-delivered student assessments in 2001. The success of the two-year pilot prompted the expansion of computerized testing throughout the curriculum for all first- and second-year medical students. In November 2004, a new state-of-the-art student computer and testing center was unveiled that is housed in the Prior Library and staffed by the integrated information technology support staff of the CKM and library.

Intellectual property and commercialization. To promote and sustain focused and effective technology transfer and commercialization of our intellectual assets, we have recently reexamined our overall strategy in these areas. Recruiting and retaining entrepreneurial faculty is one part of the equation. However, it is crucial that we provide faculty, research staff, and students with refresher training on the nuances of invention disclosures, material transfer agreements, patent basics, licensing options, and commercialization vehicles. Because we saw the value the CKM could bring to such efforts, we commissioned development of an intellectual asset management system that is now being used to track activity across the medical center campus. Synergy among our technology commercialization efforts and those of the CKM are obvious and being fostered.

Copyright and digital rights management. To facilitate important issues involved in the copyright process (e.g., steps and processes for securing copyrights, implications of the TEACH $\mathrm{Act}^{19}$ within the digital classroom) and digital rights management (e.g., licensing digital products for educational, research, and clinical use), the CKM in partnership with the library plans to provide copyright expertise, training, and staffing support resources to the medical center's faculty, staff, and students. Securing copyrights and digital rights for intellectual property in education and research will enhance the use and sharing of information in knowledge-based resources and assets.

Clinical skills and assessment center. The state-of-the-art Clinical Skills and Assessment 
Center, closely aligned with the CKM, has been created and is now in place within the Prior Library to provide high-quality clinical education and high-fidelity assessment of clinical skills and procedures. The center uses high-tech patient simulators and standardized patient encounters to give trainees experiential interactions with patients. Digital capture of these patient simulations will facilitate review, mentoring and the creation of sharable digital learning objects (e.g., patient interviewing techniques).

Comprehensive academic technology support desk. To further enhance the support of our academic IT needs, a comprehensive academic "assistance - service - knowledge" support desk was recently unveiled. Jointly staffed by library and technology support personnel, the goal is to provide users a one-stop-shop for their academic information and technology needs.

Biomedical informatics. In 2001, we created the Department of Biomedical Informatics in the OSU College of Medicine and Public Health. Alignments of the research activities of this department with the CKM's knowledge-based initiatives are now being planned. The synergy among these areas and other major digital initiatives in imaging, proteomics, gene mapping, pharmacogenomics, personalized health care, and other programs has the potential to dramatically expand and expedite the medical center's research, education, and patient care activities.

\section{Synergy Across the Mission} the CKM.

Several OSUMC initiatives are the direct result of the synergies made possible through

One example is facilitating medical students' mastery of physical examination techniques and ensuring the students' exposure to common findings. These goals can be challenging when faced with coordinating the activities of large and diverse groups of students and physician preceptors. To help overcome these challenges, multimedia developers within the CKM worked with physician educators to develop a multimedia-rich, computer-based application to augment traditional learning strategies. Focusing on seven primary content areas - head and neck, pulmonary, cardiovascular, abdominal, musculoskeletal, neurological, male and female genitalia - our "Interactive Guide to the Physical Examination" allows learners to practice selected skills (e.g., taking a blood pressure, listening to breath or heart sounds or performing a funduscopic examination) and view annotated digital video demonstrations of key clinical procedures and techniques. ${ }^{20}$ (Excerpts from this guide can be accessed via 〈http://medicine.osu.edu/exam».) While designed as an educational resource for second-year medical students, the utility of this CKM product has been realized by trainees across our health science curricula and beyond. Coupling this virtual resource with the hands-on experiences of patient simulators and standardized patient encounters available through our newly formed clinical skills center promises to strengthen the interconnections of the academic medical center's missions.

Our institution's continuing medical education (CME) activities have also benefited from the alignment of technical resources, expertise, and infrastructure within the CKM. CKM 
resources enabled the Center for $\mathrm{CME}$ to transition from traditional program delivery and take advantage of Web-enabled technologies. Designed and built by the CKM, over 2,200 OSUMC health care professionals and over 40 subscriber hospitals use a single-point, Web-accessible portal to (1) access live or archived digital video programming, (2) complete program evaluations and posttests, (3) register and pay for conferences, (4) track their CME activities and earned credits, and (5) generate certificates of completion on demand (see (http://ccme.osu.edu)). An administrative view of these Web tools allows CME administrators to track participant activities and credits and to compile and run statistics as required for CME accreditation purposes. $^{21}$ This is another example of how the medical center is leveraging CKM resources to support educational, operational, and administrative needs of clinical staff.

The need to know where expertise, know-how, and experience lie within an organization is not unique to business and industry. Academic medical centers long for fingertip access to such comprehensive information on its people and their activities to help fuel recruitment, benchmarking, outreach, development, accreditation, and interdisciplinary activities. One of the more recent knowledge-based initiatives being developed within the CKM is a project termed OSU Expertise. Designed as a comprehensive, university-wide database of faculty scholarly activities, expertise, and achievements, this innovative CKM project harnesses preexisting, canonical data sets derived from campus and off-campus data authorities (i.e., university administrative systems that support human resources, sponsored projects and technology licensing, and the off-campus Ohio Library and Information Network) and was one of the first major initiatives to grow from the university's knowledge bank initiative. ${ }^{22}$ Once fully operational, OSU Expertise will serve as a single-point resource helping to enhance interdisciplinary collaborations, recruitment, outreach, and a myriad set of administrative activities of departments and colleges across the university campus (see «https://expertise.osu.edu >).

\section{Managing Knowledge at the Crossroads}

Simply put, biomedical knowledge is at the core of our mission as an academic medical center, and we are living at the crossroads of two centuries and two extraordinary knowledge eras. By organizing traditionally disparate computing and educational technology development and support teams, we have been able to foster new knowledge initiatives, streamline support services, enhance accessibility, and appreciate economies of scale.

Combining these technological initiatives with the information, instruction and resource services of our health sciences library, we can leverage and synergize knowledge creation (i.e., basic, applied, and clinical research), knowledge dissemination (i.e., undergraduate, graduate, professional, postgraduate, and continuing education), and knowledge application (i.e., patient care therapies and devices).

The stewards of our knowledge, libraries and librarians, give us an inestimable gift by managing that knowledge — securing, organizing, retrieving, and helping expand it — by merging their traditional roles with exciting new ideas and technologies. Within the new OSUMC CKM, we are creating a single-point (yet multidimensional) knowledge entity responsive to all our 
mission areas and all our audiences, to the benefit of the patients, faculty, and staff of the medical center as well as the university, community, and beyond.

As our efforts within the CKM continue to evolve, we will continue our dialogue with peer institutions, and participate in those efforts of the Association of American Medical Colleges and other professional organizations as the academic medicine community tries to better understand how and where medical schools allocate their IT dollars, how they structure themselves organizationally, and how they are training the next generation of physicians, scientists, librarians, and information technologists in medical informatics skills and knowledge. $^{23,24}$

The authors are deeply indebted to Sara Strong for her thoughtful comments and editorial contributions during the preparation of this manuscript.

\section{References}

1. Miller J. Keynote address, DCI Conference on Knowledge Management, November 3-5, 1998. Chicago, Illinois.

2. Davenport TH, Prusak, L. Working Knowledge: How Organization Manage What They Know. Boston: Harvard Business School Press Books, 1997.

3. Anklam P. Knowledge Management: The Collaboration Thread. Bull Am Soc Inf Sci Technol. 2002;28(6):8-11.

4. Blair DC. Knowledge management: hype, hope of help? J Am Soc Inf Sci Technol. 2002; 53(12):1019-28.

5. Alavi M, Tiwana A. Knowledge integration in virtual teams: the potential role of KMS. J Am Soc Inf Sci Technol. 2002;53(12):1029-37.

6. Woodell J. Knowledge networks in the education enterprise. Multimedia Schools. 2001;8(2):48-51.

7. Walter JD. Navy Building Knowledge Management Portal «ttp://www.news. navy.mil/search/display.asp?story_id=3709>. Accessed 15 June 2005. Navy Newstand. 26 September 2002.

8. Moore ME, Garrison S, Hayes B, McLendon W. Reinventing a health sciences digital library: organizational impact. Med Ref Serv Q. 2003;22(4):76-82.

9. Terehova MV, Feodorova LM, Karpovich AV. Library as a provider of informational knowledge in the system of higher medical education. Int Inf Libr Rev. 2003;35:367-73.

10. Lee MY, Albright SA, Alkasab T, Damassa DA, Wang PJ, Eaton EK. Tufts Health Sciences Database: lessons, issues and opportunities. Acad Med. Mar. 2003;78: 254-64.

11. Candler CS, Uijtdehaage SHJ, Dennis SE. Introducing HealthEducationAssetsLibrary (HEAL): The Health Education Assets Library. Acad Med. 2003;78:249-53.

12. Lucier RE. Building a digital library for the health sciences: information space complementing information place. Bull Med Libr Assoc. 1995;83:346-50.

13. An Interview with Tom Davenport and Larry Prusak, about their new book: Working Knowledge: How 
Organizations Manage What They Know. 〈http://www.brint.com/ km/davenport/working.htm〉. Accessed 15 June 2005.

14. Stern D. New knowledge management systems: the implications for data discovery, collection development, and the changing role of the librarian. J Am Soc Inf Sci Technol. 2003;54(12):1138-40.

15. Vassallo P. The knowledge continuum: organizing for research and scholarly communication. Internet Research: Electronic Networking, Applications and Policy. 1999;9(3):232-42.

16. Association of Academic Health Sciences Libraries. Building on Success: Charting the Future of Knowledge Management with the Academic Health Center. AAHSL Charting the Future Task Force, 2003.

17. Bell SJ, Shank J. The blended librarian a blueprint for redefining the teaching and learning role of academic librarians. Coll Res Libr News. 2004;65(7):372-75.

18. Wolf FM, Schaad DC, Carline JD, Dohner CW. Medical education research at the University of Washington School of Medicine: lessons from the past and potential for the future. Acad Med. 2004;79:1007-11.

19. Technology, Education and Copyright Harmonization (TEACH) Act http://www.arl.org/info/frn/copy/TEACH. html〉. Accessed 15 June 2005. Association of Research Libraries, Washington, DC.

20. Kreger C, Knutson D, Fish C, Stewart C, Cain TJ, Gabel LL. An interactive multimedia web-based program to enhance the learning of physical examination skills by medical students. J Gen Intern Med. 2001;16:81-82.

21. Finneran CN, Fish CA, Davis P, Cain TJ. Continuing medical education: coupling innovative web technologies to enhance and extend your educational mission. Paper presented at Slice of Life Conference for Medical Multimedia Developers and Educators, University of Pennsylvania and Drexel University, Philadelphia, PA, June 2003.

22. Branin JJ. Knowledge management in academic libraries: building the knowledge bank at the Ohio State University. J Libr Admin. 2003;39(4):41-56.

23. Group on Information Resources 〈http:// www.aamc.org/members/gir/〉. Accessed 10 June 2005. Association of American Medical Colleges, Washington, DC.

24. Cohen J, President, Association of American Medical Colleges, Announcement of Medical Informatics Survey. E-mail communication to Education Deans and AAMC Group on Information Resources members, 20 January 2005. 